\title{
Accuracy of Zero Inflated Generalized Poisson Exponentially Moving Average Control Chart
}

\author{
Keakuratan Peta Kendali Zero-Inflated Generalized Poisson Exponential \\ Moving Average
}

\author{
L.M. Jamaluddin Al Afgani*1 ${ }^{1}$, Erna Tri Herdiani ${ }^{\# 2}$, Nurtiti Sunusi ${ }^{\# 3}$
}

\begin{abstract}
The Zero-Inflated Generalized Poisson (ZIGP) distribution is a case-based distribution where the discrete data has a large number of zeros and an overdispersion occurs, i.e. the variance is greater than the mean value. The purpose of this study is to determine the Exponential Weight Moving Average (EWMA) control chart with the assumption that the data has a Zero-Inflated Generalized Poisson (ZIP) distribution. The results show that the ARL value of the ARL ZIGP EWMA control chart has better accuracy when compared to when using the ZIP EWMA control chart on ZIGP distributed data. This is indicated by the smaller ARL value compared to the ZIP EWMA control chart, namely when $\varphi=1.4$, and $\varphi=0.6$. So that the ARL ZIGP EWMA control chart has a fairly good accuracy in detecting out of control conditions for ZIGP distributed data. In addition, the modified ARL shows the same values before and after the modification for the underdispersion data and shows a larger or negative value for the overdispersion data. This can eliminate or reduce errors in analyzing the accuracy of the control chart.
\end{abstract}

Keywords : Overdispersion, Underdispersion, Poisson distribution, Generalized Poisson distribution (GP), Zero-Inflated Poisson distribution (ZIP), Zero-Inflated Generalized Poisson distribution (ZIGP), EWMA control chart

\begin{abstract}
Abstrak
Distribusi Zero-Inflated Generalized Poisson (ZIGP) merupakan distribusi berdasarkan kasus dimana pada data diskrit terdapat nilai nol yang begitu banyak dan terjadi overdispersi yaitu variansi lebih besar dari nilai mean. Adapun tujuan penelitian ini adalah menentukan peta kendali Exponential Weight Moving Average (EWMA) dengan asumsi data berdistribusi Zero-Inflated Generalized Poisson (ZIP). Hasil penelitian menunjukan nilai ARL peta kendali ARL ZIGP EWMA memiliki keakuratan yang lebih baik jika dianding saat menggunakan peta kendali ZIP EWMA pada data berdistribusi ZIGP. Hal ini ditunjukan dengan nilai ARLnya yang lebih kecil dibanding dengan peta kendali ZIP EWMA yaitu pada saat $\varphi=1.4$, dan $\varphi=0,6$. Sehingga peta kendali ARL ZIGP EWMA memiliki keakuratan yang cukup baik dalam mendetekasi keadaan out of control untuk data berdistribusi ZIGP. Selain itu, ARL modifikasi menujukan nilai yang sama sebelum dan sesudah modifikasi untuk data underdispersi dan menunjukan nilai yang lebih besar atu negative pada data overdispersi. Hal ini dapat menghilangkan atau mengurangi kesalahan dalam menganalisis keakuratan peta kendali

Kata Kunci : Overdispersi, Underdispersi,distribusi Poisson, distribusi Generalized Poisson $(G P)$, distribusi Zero-Inflated Poisson (ZIP), distribusi Zero-Inflated Generalized Poisson $(Z I G P)$, peta kendali kendali EWMA.
\end{abstract}

* Program Studi Magister Statistika, FMIPA- Universitas Hasanuddin

Email address: alafgani1393@gmail.com ${ }^{1}$, ,erna@sci.unhas.ac.id ${ }^{2}$,nurtiti@sci.unhas.ac.id ${ }^{3}$

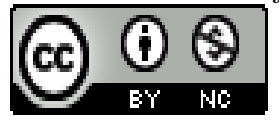

This work is licensed under a Creative Commons Attribution-NonCommercial 4.0 International License 


\section{Jurnal Matematika, Statistika \& Komputasi}

\section{L.M. Jamaluddin Al Afgani, Erna Tri Herdiani, Nurtiti Sunusi}

\section{Pendahuluan}

Karakteristik kualitas tidak selalu dalam bentuk data kontinyu tapi juga dalam bentuk data atribut. Data atribut dapat dihasilkan ketika memonitor urutan jumlah diskrit seperti memeriksa jumlah item yang rusak per unit. Data hitungan ini sering dimodelkan dengan distribusi Poisson. Pada pengendalian kualitas proses produksi, peta kendali poisson digunakan untuk mengontorol proses produksi dimana mean dan variansi dari sampel sama. Pada kenyataannya data atribut seringkali memperlihatkan perbedaan variansi dan mean sampel yaitu variansi sampel lebih besar dari mean sampel (overdispersi) atau vairansi sampel lebih kecil dari mean sampel (underdispersi) [10].

Ada beberapa distribusi yang telah diperkenalkan oleh para ahli untuk mengatasi masalah overdispersi dan underdispersi. Salah satu model yang dapat mengatsi masalah tersebut adalah distribusi generalized Poisson (GP). Distribusi GP merupakan distribusi perluasan dari distribusi Poisson, Distribusi GP dapat mengatasi masalah overdispersi tetapi tidak dapat mengatasi masalah zero inflated atau kasus dengan data yang ada terlalu banyak mengandung nilai nol. Salah satu distribusi yang dapat mengatasi masalah tersebut adalan distribus zero inflated Poisson (ZIP). Akan tetapi, model ZIP ini kurang tepat untuk mengatasi masalah underdispersi. Sehingga diperlukan suatu distribusi lain yang yang tepat untuk mengatasi permasalahan tersebut. Salah satunya adalah dengan menggunakan distribusi zero inflated generalized Poisson (ZIGP) [7].

Menurut [5] distribusi ZIGP merupakan perluasan dari distribusi Poisson dan merupakan gabungan dari distribusi ZIP dan Distribusi GP. Sehingga distribusi ZIGP ini dapat diterapkan pada data atribut yang menunjukan sifat overdispersi atau underdispersi serta mempunyai frekuensi data nol yang lebih banyak.

Peta kendali yang umum digunakan untuk mengontrol sebuah proses produksi berdistribusi poisson ada peta kendali-C. Peta kendali-C dikenal efektif dalam mendeteksi pergeseran besar pada proses produksi. Namun dalam proses produksi terdapat pergeseran-pergeseran nilai atau terjadi suatu rentang proses yang kecil maka peta kendali-c kurang sensitif dalam mendeteksinya. Peta kendali Cumulatif Sum (CUSUM) dan Exponentially Weighted Moving Average (EWMA) merupakan alternatif yang tepat untuk masalah tersebut [2]. Namun dalam paper ini hanya akan dikaji mengenai peta kendali EWMA. Peta kendali EWMA yang dikaji adalah untuk data berdistribusi ZIGP. Kemudian dilakukan analisis ARL berdasarkan hasil kajian tersebut.

\section{Tinjauan Pustaka}

\subsection{Peta Kendali Exponential Weight Moving Average (EWMA)}

Peta kendali Exponentially Weighted Moving Average atau dapat disingkat EWMA diperkenalkan pertama kali oleh S.W. Roberts pada tahun 1959 dan digunakan untuk memonitor proses dan mendeteksi adanya faktor terusut yang terlihat dari adanya pergeseran terus menerus dalam suatu proses. Peta kendali EWMA ini terutama digunakan untuk mendeteksi adanya pergeseran nilai mean yang kecil dalam suatu proses produksi. Dalam suatu proses produksi tertentu, pergeseran nilai mean dari suatu ukuran hasil produksi memiliki pengaruh yang cukup besar terhadap biaya produksi atau kualitas dari hasil produksi itu sendiri.

Berdasarkan penelitian Box dan Jenkins pada tahun 1976 serta Montgomery dan Johnson pada tahun 1976, peta kendali EWMA digunakan secara luas dalam pemodelan runtun waktu (time series) dan peramalan (forecasting).. Rumus untuk titik plot Peta kendali EWMA dapat didefinisikan sebagai berikut:

dengan: $Z_{t}=$ nilai EWMA ke-t

$$
Z_{t}=\xi X_{t}+(1-\xi) Z_{t-1} \quad, \mathrm{t}=1,2,3, \ldots
$$

$\xi \quad=$ parameter bobot yang bernilai antara 0 dan 1 .

$X_{t}=$ nilai pengamatan $\mathrm{ke}-\mathrm{t}, \mathrm{t}=1,2, \ldots \mathrm{t}$ 


\section{Jurnal Matematika, Statistika \& Komputasi}

\section{L.M. Jamaluddin Al Afgani, Erna Tri Herdiani, Nurtiti Sunusi}

$\mathrm{t} \quad=$ banyaknya pengamatan

$Z_{t-1}=$ nilai EWMA sebelumnya

dari persamaan ini, dapat diketahui rata-rata dan variansi model EWMA masing- masing adalah:

$$
E\left(Z_{t}\right)=\mu_{0}
$$

dan

$$
\operatorname{Var}\left(Z_{t}\right)=\frac{\lambda \xi}{2-\xi}
$$

\subsection{Distribusi Zero-Infalted Poisson (ZIP)}

Model Zero-Infalted Poisson (ZIP) merupakan distribusi campuran sederhana untuk data diskrit dengan banyak peristiwa nol. Suatu variabel acak $x$ dikatakan berdistribusi ZIP, jika dan hanya jika fungsi peluangnya berbentuk [1] [2]:

$$
P_{x}(\omega, \lambda)=\left\{\begin{array}{cc}
\omega+(1-\omega) e^{-\lambda} & , x=0 \\
\frac{(1-\omega) e^{-\lambda} \lambda^{x}}{x !} & , x>0
\end{array}\right.
$$

\subsection{Distribusi Zero-Infalted Generalized Poisson (ZIGP)}

Distribusi ZIGP merupakan salah satu distribusi yang menjelaskan data diskrit dengan banyaknya data yang bernilai nol (zero-inflated) dan terjadi overdispersi. Famoye dan Singh dalam [7] mendefinisikan fungsi densitas probabilitas ZIGP sebagai gabungan dari fungsi densitas Probablititas ZIP dan GP, sehingga fungsi densitas probabilitas distribusi ZIGP dapat dituliskan sebagai berikut,

$$
P_{x}=\left\{\begin{array}{cl}
\omega+(1-\omega) \exp (-\lambda \varphi) & , y=0 \\
(1-\omega) \exp \left(\frac{1}{\varphi}(\lambda+x(\varphi-1))\right) \frac{\lambda(\lambda+y(\varphi-1))^{x-1}}{\varphi^{x} x !} & , y>0
\end{array}\right.
$$

dimana $\omega$ adalah proporsi nol kecacatan berlebih didalam suatu sampel unit, $\lambda$ merupakan rata-rata dari kecacatan didalam suatu sampel unit, sedangkan $\varphi$ menunjukan disperse atau rasio varian dan rata-rata dari x. Rata-rata dari data berdistribusi ZIGP adalah $E(X)=(1-\omega) \lambda$ dan $\operatorname{Var}(X)=(1-\omega) \lambda\left(\varphi^{2}+\lambda \omega\right)$.

\subsection{Average Run Length Markov Chain}

Average Run Length (ARL) out of control.adalah jumlah rata-rata titik sampel yang harus diplot pada bagan kendali sebelum suatu titik menunjukkan keadaan tak terkendali. Dalam [13] dijelaskan bahwa Woodall dan Mahmoud mengusulkan resistansi sinyal merupakan standar deviasi dari suatu distribusi yang tidak mengarahkan ke sinyal out of control. Pada ARL out of control, semakin kecil ARL maka semakin kecil pula ekspektasi jumlah sampel yang diperlukan sampai terdapat sinyal out of control. Hal ini berarti semakin kecil ARL, semakin cepat grafik kendali mendeteksi adanya pergeseran [4]. Dengan adanya ARL, jenis peta kendali terbaik dapat dipilih. Jika ARL out of control, semakin kecil nilai ARL maka semakin baik jenis peta kendali yang bersangkutan [9]. ARL out of control didefinisikan oleh:

$$
A R L=Q(I-Q)^{-1} 1
$$

Menurut [8] salah satu metode yang banyak digunakan dalam menentukan nilai ARL pada peta kendali EWMA yaitu metode rantai markov yang dikembangkan oleh Brook dan Evans yaitu:

$$
Q_{i j}=P\left(\left(\frac{H_{j}+\delta-(1-\xi) H_{i}}{\xi}-\mu\right) \frac{1}{\sigma}\right)-P\left(\left(\frac{H_{j}-\delta-(1-\xi) H_{i}}{\xi}-\mu\right) \frac{1}{\sigma}\right)
$$

dimana $\quad H_{i}=L C L+\delta, \quad i=-m,-m+1, \ldots, m$

$$
\begin{aligned}
& p=2 m+1 \\
& \delta=(U C L-L C L) / 2 p
\end{aligned}
$$




\section{Jurnal Matematika, Statistika \& Komputasi}

\section{L.M. Jamaluddin Al Afgani, Erna Tri Herdiani, Nurtiti Sunusi}

$H_{i}$ : resistensi sinyal

$p \quad$ : jumlah sub interval

$\delta \quad:$ setengah lebar tiap-tiap interval

\section{Hasil Penelitian}

\subsection{Kontruksi Peta Kendali ZIGP EWMA}

Mengingat bahwa pengambilan sampel yang berulang diambil dari urutan kualitas ukuran $X_{1}, X_{2}, \ldots, X_{n}$ dengan asumsi bahwa $X_{1}, X_{2}, \ldots, X_{n}$ adalah variabel acak Poisson yang terdistribusi saling bebas dan indentik dengan rataan $\mu$. Proses dikatakan dalam kontrol ketika $\mu=\mu_{0}$ dan berada diluar kontrol ketika $\mu \neq \mu_{0}$. Untuk memantau proses tersebut, dapat digunakan peta kendali EWMA yang pertama kali diperkenalkan oleh Roberts tahun1959.

dan

$$
Z_{t}=\xi X_{t}+(1-\xi) Z_{t-1} \quad, \mathrm{t}=1,2,3, \ldots
$$

dengan: $Z_{0}=$ nilai awal

$$
Z_{0}=\mu_{0}
$$

$\mu_{0}=$ rata- rata

Karena $X_{t}$ berdistribusi ZIGP dengan $\operatorname{Var}(X)=(1-\omega) \lambda\left(\varphi^{2}+\lambda \omega\right)$ dan $E(X)=(1-\omega) \lambda$ maka nilai ratarata dan variansi dari EWMA adalah sebagai berikut:

$$
\begin{gathered}
E\left(Z_{t}\right)=(1-\omega) \lambda \\
\sigma_{Z_{t}}^{2}=\frac{\xi(1-\omega) \lambda(\varphi 2+\lambda \omega)}{2-\xi}\left(1-(1-\xi)^{2 t}\right)
\end{gathered}
$$

Sehingga Center Line (CL), Upper Control Limit (UCL) dan Lower Control Limit (LCL) peta kendali ZIGP EWMA adalah

$$
\begin{aligned}
& U C L=(1-\omega) \lambda+L \sqrt{\frac{\xi(1-\omega) \lambda(\varphi 2+\lambda \omega)}{2-\xi}\left(1-(1-\xi)^{2 t}\right)} \\
& C L=(1-\omega) \lambda \\
& L C L=(1-\omega) \lambda-L \sqrt{\frac{\xi(1-\omega) \lambda(\varphi 2+\lambda \omega)}{2-\xi}\left(1-(1-\xi)^{2 t}\right)}
\end{aligned}
$$

Untuk data diskrit seharusnya tidak ada data yang bernilai negatif sehingga pada batas kendali bawah akan bernilai nol ketika menunjukan hasil dengan nilai negatif. Ketika peta kendali EWMA telah berjalan untuk beberapa periode, $\left(1-(1-\lambda)^{2 t-2}\right) \rightarrow 1$ untuk $t$ semakin besar [9]. Sehingga batas kontrol mendekati nilai stabil yang diberikan oleh persamaan berikut:

$$
\begin{aligned}
U C L & =(1-\omega) \lambda+L \sqrt{\frac{\xi(1-\omega) \lambda(\varphi 2+\lambda \omega)}{2-\xi}} \\
C L & =(1-\omega) \lambda \\
L C L & =\min \left\{0, \quad(1-\omega) \lambda-L \sqrt{\frac{\xi(1-\omega) \lambda(\varphi 2+\lambda \omega)}{2-\xi}}\right\}
\end{aligned}
$$

Jika $\varphi=1$ dan $0 \leq \omega<1$ maka peta kendali ZIGP EWMA akan menjadi peta kendali ZIP EWMA yaitu: 


\section{Jurnal Matematika, Statistika \& Komputasi}

\section{L.M. Jamaluddin Al Afgani, Erna Tri Herdiani, Nurtiti Sunusi}

$$
\begin{aligned}
& U C L=(1-\omega) \lambda+L \sqrt{\frac{\xi(1-\omega) \lambda(1+\lambda \omega)}{2-\xi}} \\
& C L=(1-\omega) \lambda \\
& L C L=\min \left\{0, \quad(1-\omega) \lambda-L \sqrt{\frac{\xi(1-\omega) \lambda(1+\lambda \omega)}{2-\xi}}\right\}
\end{aligned}
$$

\subsection{Modifikasi Average Run Length (ARL) Markov Chain}

Penerapan peta kendali ZIP EWMA pada data berdistribusi ZIGP mengakibatkan dapat terjadinya false alarm. False alarm adalah suatu kondisi dimana peta kendali mendeteksi keadaan out of control padahal data tersebut masih terdapat dalam keadaan terkendali. Dengan menggunakan ARL Markov Chain yang dikembangkan oleh Brook dan Evans, keadaan false alarm tidak dapat terdeteksi. ARL yang dihasilkan saat terjadinya false alarm menunjukan kesensitifitas yang tinggi untuk mendeteksi keadaan out of control. Hal ini terjadi diakibatkan bercampurnya data yang out of control dan data in control. Selain itu, nilai standar deviasi yang digunakan pada peta kendali lebih kecil dari yang seharusnya. Kasus tersebut sering terjadi ketika menggunakan peta kendali ZIP EWMA pada distribusi ZIGP untuk data overdispersi.

Dalam memodifikasi ARL, diharapkan nilai ARL yang dihasikan sama sebelum dan sesudah modifikasi untuk data underdispersi. Karena $\sigma_{Z I P}>\sigma_{Z I G P}$ maka nilai $A R L_{Z I P}>A R L_{Z I G P}$. Pada data overdispersi, diharapkan nilai ARL sesudah modifikasi akan lebih besar di banding sebelum dimodifikasi. Hal ini dilkukan untuk menunjukan telah terdapat false alarm dalam peta kendali. Untuk itu kami mempertimbangkan untuk merubah matriks transisi Q menjadi:

$$
\overline{Q_{l, J}}=P\left(G_{j},<X_{t}<J_{i}\right)
$$

$$
\text { dengan } \begin{aligned}
P\left(J_{j}\right) & =P\left(\left(\frac{H_{j}+\delta-(1-\xi) H_{i}}{\xi}-\mu\right) \frac{1}{\sigma}\right)+E \\
P\left(G_{j}\right) & =P\left(\left(\frac{H_{j}-\delta-(1-\xi) H_{i}}{\xi}-\mu\right) \frac{1}{\sigma}\right)-E
\end{aligned}
$$

dan E adalah matriks transisi false alarm.

$\overline{Q_{l, j}}$ dapat disederhanakan menjadi:

$$
\begin{aligned}
\overline{Q_{l, j}}=P\left(G_{j},<X_{t}\right. & \left.<J_{i}\right) \\
& =P\left(\left(\frac{H_{j}+\delta-(1-\xi) H_{i}}{\xi}-\mu\right) \frac{1}{\sigma}\right)+E-P\left(\left(\frac{H_{j}+\delta-(1-\xi) H_{i}}{\xi}-\mu\right) \frac{1}{\sigma}\right)+E \\
\overline{Q_{l j}} & =Q_{i j}+2 E
\end{aligned}
$$

Sehingga nilai ARL saat terjadinya false alarm yaitu:

$$
A R L=(Q+2 E)(I-(Q+2 E))^{-1} 1
$$

pada saat terjadinya overdispersi, false alarm sering terjadi diatas garis UCL. Hal ini diakibatkakan $\mathrm{UCL}_{\mathrm{ZIP}}<\mathrm{UCL}_{\mathrm{ZIGP}}$, sehingga: 


\section{Jurnal Matematika, Statistika \& Komputasi}

\section{L.M. Jamaluddin Al Afgani, Erna Tri Herdiani, Nurtiti Sunusi}

$$
\delta_{E}=\frac{U C L_{Z I G P}-U C L_{Z I P}}{2 p}
$$

E dapat dihitung menggunakan:

$$
E_{i j}=P\left(\left(\frac{L_{j}+\delta_{E}-(1-\xi) L_{i}}{\xi}-\mu\right) \frac{1}{\sigma}\right)-P\left(\left(\frac{L_{j}-\delta_{E}-(1-\xi) L_{i}}{\xi}-\mu\right) \frac{1}{\sigma}\right)
$$

Sayangnya kami hanya dapat membuktian ARL modifikasi ini dengan simulasi dan hasil simulasi. Akan tetapi kami dapat menyajikan hasil yang cukup bagus dalam simulasi yang kami hasilkan.

\subsection{Simulasi dan Hasil Simulasi}

Pada sesi ini akan dibandingkan kinerja dari peta kendali ZIP EWMA dan ZIGP EWMA. Data simulasi yang digunakan berjumlah 100 dan dibangkitkan dengan asumsi data berdistribusi ZIGP dengan $\lambda=3$. Untuk membatasi jumlah dari data simulasi, akan dipilih $\omega=\{0,0.4,0.8\}$ dan $\varphi=\{0.6,1.4\}$, sehingga data simulasi berjumlah 9 jenis dengan bobot $(\xi)=\{0.2,0.5,0.7,0.8,0.9\}$. Kemudian untuk menilai kinerja peta kendali ZIP EWMA dan ZIGP EWMA dilakukan perbandingan nilai ARL untuk menilai kinerja peta kendali tersebut. Pertama akan digunakan ARL out of control sebelum dimodifikasi dan kedua akan digunakan ARL yang telah dimodifikasi. Nilai ARL yang dihasilkan dari data simulasi dapat dilhat pada tabel. 3.1.

\begin{tabular}{|c|c|c|c|c|c|c|c|}
\hline \multirow{3}{*}{$\varphi$} & \multirow{3}{*}{$\xi$} & \multicolumn{2}{|c|}{$\omega=0$} & \multicolumn{2}{|c|}{$\omega=0.4$} & \multicolumn{2}{|c|}{$\omega=0.8$} \\
\hline & & ZIP & ZIGP & ZIP & $\overline{\mathrm{ZIGP}}$ & ZIP & ZIGP \\
\hline & & EWMA & EWMA & EWMA & EWMA & EWMA & EWMA \\
\hline \multirow{5}{*}{0.6} & 0.2 & 4.8271 & 1.9010 & 6.4640 & 4.3708 & 64.0151 & 57.6569 \\
\hline & 0.5 & 4.4686 & 1.2031 & 5.5931 & 3.9969 & 33.8041 & 23.6291 \\
\hline & 0.7 & 31.6849 & 1.2608 & 6.8624 & 3.1967 & 35.0042 & 13.4561 \\
\hline & 0.8 & 47.2732 & 2.1257 & 6.8624 & 4.2095 & 14.6286 & 14.6286 \\
\hline & 0.9 & 390.2427 & 2.1257 & 7.0292 & 4.2095 & 14.6286 & 14.6286 \\
\hline \multirow{5}{*}{1} & 0.2 & 2.0982 & 2.0982 & 4.5411 & 4.5411 & 34.0796 & 34.0796 \\
\hline & 0.5 & 1.4206 & 1.4206 & 3.9691 & 3.9691 & 18.2588 & 18.2588 \\
\hline & 0.7 & 1.4816 & 1.4816 & 3.4197 & 3.4197 & 12.7978 & 12.7978 \\
\hline & 0.8 & 1.8347 & 1.8347 & 3.7245 & 3.7245 & 1.3094 & 1.3094 \\
\hline & 0.9 & 1.8347 & 1.8347 & 3.7245 & 3.7245 & 1.3094 & 1.3094 \\
\hline \multirow{5}{*}{1.4} & 0.2 & 1.5977 & 2.3187 & 4.1859 & 5.8312 & 17.8332 & 26.5153 \\
\hline & 0.5 & 0.9038 & 1.7380 & 3.4383 & 3.4383 & 12.5873 & 17.6348 \\
\hline & 0.7 & 0.9957 & 1.7208 & 2.9535 & 3.6721 & 1.2174 & 1.3281 \\
\hline & 0.8 & 0.9957 & 1.9320 & 2.9807 & 3.8867 & 1.1880 & 1.2723 \\
\hline & 0.9 & 0.9957 & 1.9320 & 2.9141 & 3.8867 & 1.1096 & 1.1875 \\
\hline
\end{tabular}

Tabel 3.1. Perbandingan Nilai ARL ZIP EWMA dan ZIGP EWMA 


\section{Jurnal Matematika, Statistika \& Komputasi}

\section{L.M. Jamaluddin Al Afgani, Erna Tri Herdiani, Nurtiti Sunusi}

Kemudian nilai ARL yang telah dimodifikasi dapat dilihat pada tabel 3.2. dan gambar 3.1.

Tabel 3.2. ARL Modofikasi Peta Kendali ZIP EWMA, ZIGP EWMA

\begin{tabular}{ccccccc}
\hline & & \multicolumn{2}{c}{$\varphi=0.6$} & & \multicolumn{2}{c}{$\varphi=1.4$} \\
\cline { 3 - 4 } \cline { 6 - 7 }$\omega$ & $\xi$ & ARL ZIGP & ARL ZIP & & ARL ZIGP & ARL ZIP \\
& & EWMA & EWMA & & EWMA & EWMA \\
\hline \multirow{4}{*}{0} & 0.2 & 1.901 & 3.598406 & & 2.3187 & 58.1081 \\
& 0.5 & 1.2031 & 4.468591 & & 1.738 & 2.014902 \\
& 0.7 & 1.2608 & 31.68485 & & 1.7208 & -459614 \\
& 0.8 & 2.1257 & 47.27321 & & 1.932 & 2.594486 \\
& 0.9 & 2.1257 & 390.2427 & & 1.932 & 2.375632 \\
& 0.2 & 4.3708 & 6.463992 & & 5.8312 & -398315 \\
0.4 & 0.5 & 3.9969 & 5.693091 & & 3.4383 & 4.488945 \\
& 0.7 & 3.1967 & 6.862369 & & 3.6721 & 4.242007 \\
& 0.8 & 4.2095 & 6.862369 & & 3.8867 & 2.980696 \\
& 0.9 & 4.2095 & 7.029242 & & 3.8867 & 10.70107 \\
& 0.2 & 57.6569 & 64.0151 & & 26.5153 & 0.626865 \\
0.8 & 0.5 & 23.6291 & 33.80409 & & 17.6348 & -287.01 \\
& 0.7 & 13.4561 & 35.00417 & & 1.3281 & 1.329815 \\
& 0.8 & 14.6286 & 14.6286 & & 1.2723 & 1.87979 \\
& 0.9 & 14.6286 & 14.6286 & & 1.1875 & 1.213842 \\
\hline
\end{tabular}

ARL ZIP EWMA:
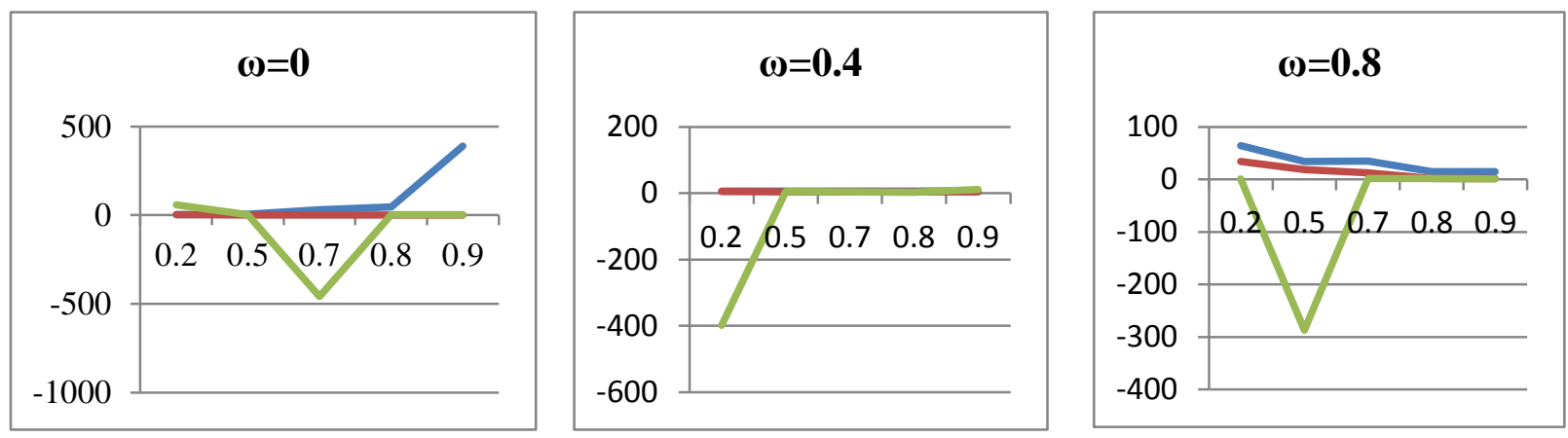

ARL ZIGP EWMA:
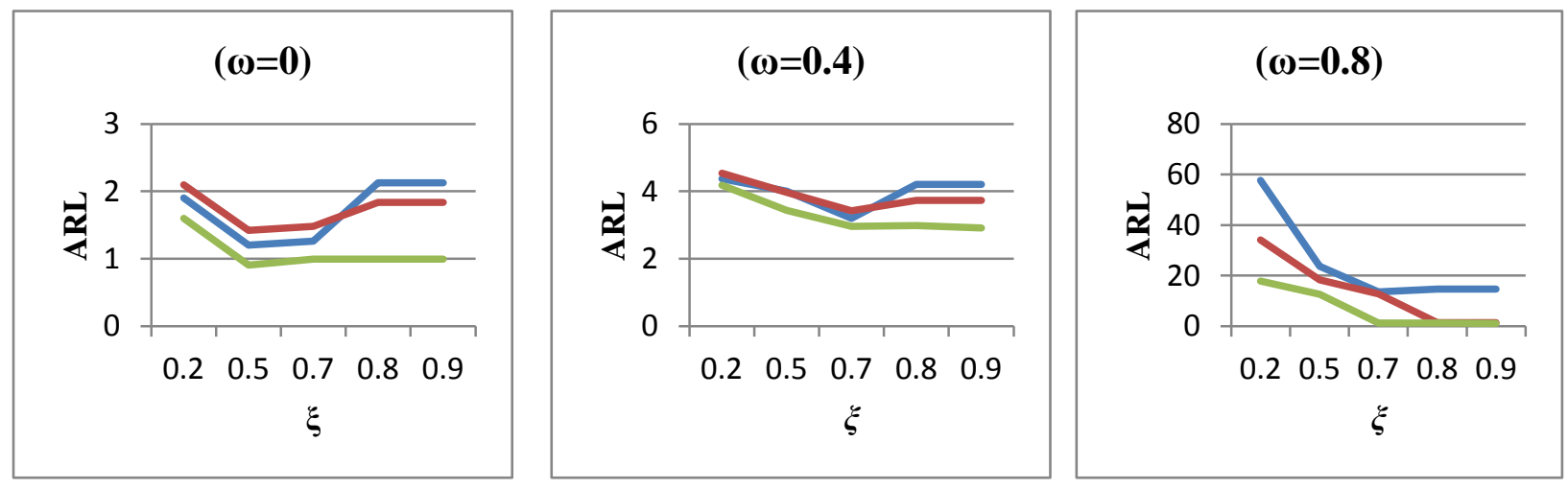

$-\varphi=0.6-\varphi=1-\varphi=1.4$ 


\section{Jurnal Matematika, Statistika \& Komputasi}

\section{L.M. Jamaluddin Al Afgani, Erna Tri Herdiani, Nurtiti Sunusi}

Gambar 3.1. Perbandingan Nilai ARL Modifikasi

Nilai ARL modifikasi mengalami fluktuasi karena terdapat nilai ARL yang cukup jauh nilainya dibanding nilai ARL sebelum modifikasi untuk nilai $\varphi$ dan $\omega$ yang sama dan nilai $\xi$ yang berbeda. Hal ini ditunjukan pada $\omega=0, \varphi=1.4, \xi=0.7$, dengan nilai ARL $-45,9614$, dibanding pada $\omega=0$, $\varphi=1.4, \xi=0.9$, dengan nilai ARL 2.375632. Nilai ARL negatif menunjukan terdapat banyak false alarm yang terjadi. Pada kasus overdispersi kejadian tersebut selalu terjadi, namun pada $\xi$ yang cukup dekat dengan 1, peta kendali ZIP EWMA memberikan keakuratan yang mendekati peta kendali ZIGP. Pada kasus underdipersi nilai ARL modifikasi menunjukan hasil yang sama dengan nilai ARL out of control. Tentu saja. ini sesuai dengan yang diharapkan sebelumnya.

\section{Kesimpulan}

Penelitian ini bertujuan untuk mengembangkan peta kendali EWMA berdasarkan distribusi ZIGP. Pada data simulasi menunjukan nilai ARL peta kendali ARL ZIGP EWMA memiliki keakuratan yang lebih baik jika dianding saat menggunakan peta kendali ZIP EWMA pada data berdistribusi ZIGP. Hal ini ditunjukan dengan nilai ARLnya yang lebih kecil dibanding dengan peta kendali ZIP EWMA yaitu pada saat $\varphi=1.4$, dan $\varphi=0,6$. Sehingga peta kendali ARL ZIGP EWMA memiliki keakuratan yang cukup baik dalam mendetekasi keadaan out of control untuk data berdistribusi ZIGP. Selain itu, ARL modifikasi menujukan nilai yang sama sebelum dan sesudah modifikasi untuk data underdispersi dan menunjukan nilai yang lebih besar atu negative pada data overdispersi. Hal ini dapat menghilangkan atau mengurangi kesalahan dalam menganalisis keakuratan peta kendali.

\section{DAFTAR PUSTAKA}

[1] Alevizakos, V., \& Christos K., 2019. Monitoring Of Zero-Inflated Poisson Processes With EWMA and DEWMA Control Charts. Quality and Reliabilty Engineering Intrnational, Vol. 36, No. 1, pp. 88-111. https://doi.org/10.1002/qre.2561.

[2] Aya, A.A., Nesma A.S., \& Mahmoud A.M., 2019. An Adaptive EWMA Control Chart For Monitoring Zero-Inflated Poisson Processes . Communications in Statistics - Simulation and Computation. http://doi.org/10.1080/03610918.2019.1676437.

[3] Consul, P.C., Jain G.C., 1973. A Generalized Of The Poisson Distributions. Technometrics, Vol. 15, No.4, pp. 791-799. http://doi.org/10.1080/00401706.1973.10489112.

[4] Edwin R, Van Den Heuvel., Stephan Van Driel A.W., \& Zhuozhao Zhan., 2020. A Bivariate ZeroInflated Poisson Control Chart: Comments And Corrections On Earlier Results. Communications in Statistics - Theory and Methods. http://doi.org/10.1080/03610926.2020.1736304.

[5] Famoye, F., Singh K.P., 2003. On inflated Generalized Poisson Regression Models. Advance and Applied Statistics, Vol. 3, No.2, pp. 145-158.

[6] Famoye, F., Singh K.P., 2006. Zero-Inflated Generalized Poisson Regression Model With An Application To Domestic Violence Data, Journal of Data Science, Vol. 4, No. 1, pp. 117-130. http://doi.org/10.6339/JDS.2006.04(1).257. 


\section{Jurnal Matematika, Statistika \& Komputasi}

\section{L.M. Jamaluddin Al Afgani, Erna Tri Herdiani, Nurtiti Sunusi}

[7] Katemee, N., Tidadeaw M., 2016. Control Charts for Monitoring the Zero-Inflated Generalized Poisson Processes. International J. of Math. Sci. \& Engg. Appls, Vol. 10, No.3, pp. 173-181.

[8] Montgomery, D.C., 2006. Introduction to Statistical Quality Control 5th Edition. John Wiley \& Sons Inc., New York.

[9] Montgomery, D.C., 2009. Introduction To Statistical Quality Control Sixth Edition. John Wiley \& Sons Inc., New York.

[10] Noriszura, I., Jemain, A.A., 2007. Handling Overdispersion with Negative Binomial and Generalized Poisson Regression Models. Casualty Actuarial Society Forum. https://www.researchgate.net/publication/252461712_Handling_Overdispersion_with_Negative_Bi nomial_and_Generalized_Poisson_Regression_Models. [21 Oktober 2020].

[11] Patel, A.K., Divecha J., 2011. Modified Exponentially Weighted Moving Average (EWMA) Control Chart for an Analytical Process Data. Journal of Chemical engineering and Material Sciense, Vol. 2, No.1, 12-20. https://academicjournals.org/journal/JCEMS/article-full-textpdf/466796E1469. [21 Oktober 2020].

[12] Walpole, R.E., Dkk., 2003. Probabilitas dan Statistika untuk Teknik dan Sains. PT Prehallindo, Jakarta.

[13] Woodall, W.H., Mahmoud A. M., 2005. The Inertial Properties of Quality Control Charts. Technometrics, Vol. 47, No. 4, pp. 425-436. https://doi.org/10.1198/004017005000000256. 